\title{
GÉNERO, SEXUALIDAD Y TRANSICIÓN SUBJETIVA EN MÉXICO: CONSTRUCCIÓN DE LA ADOLESCENCIA FEMENINA EN LAS CELEBRACIONES DE 15 AÑOS
}

Lisett María Gutiérrez Domínguez

RESUMEN

En el presente artículo se discute el tema de la articulación entre el género, la edad y la clase social en los procesos de construcción subjetiva que ocurren durante el tránsito de la infancia a la adolescencia. A partir de la relación entre los conceptos de posiciones de sujeto, interpelación, performatividad y cita, se analiza cómo esta transición para las adolescentes mexicanas es asociada con la celebración de los 15 años, a pesar de que muchas familias rechazan el patrón de fiesta típica y las normas de género vinculadas a ese patrón. Como material empírico para la discusión, se presentan dos casos de quinceañeras que, aunque no hacen una fiesta típica, tanto ellas como sus familiares se sienten interpeladas por la llegada de los 15 años, reconocen la existencia de una tradición asociada a este momento de la vida, manifiestan algún tipo de rechazo a dicha tradición, debaten acerca de formas alternativas de celebrar, y facilitan procesos de transición subjetiva hacia la feminidad adolescente, o bien, se resisten a ellos, postergándolos.

\section{PALABRAS CLAVE}

Género, Adolescencia, Quinceañera, Subjetividad, Interpelación, Performatividad

\section{ABSTRACT}

In this paper the articulation between gender, age and social class in the subjective construction processes that occur during the transition from childhood to adolescence is discussed. Based on the relationship between the concepts of subject positions, interpellation, performativity and citation, I analyze how this transition is associated with the celebration of 15 turning for Mexican adolescents, although many 
families reject the typical feast pattern and the gender norms associated with it. As empirical material for discussion, two cases of quinceañeras who do not make a typical feast are presented, showing how they and their families feel challenged by the arrival of 15 years, recognize the existence of a tradition associated with this point in life, manifest some kind of rejection of that tradition, debate about alternative ways to celebrate, and facilitate processes of subjective transition to adolescent femininity, or resist and delay them.

KEY WORDS

Gender, Adolescence, Quinceañera, Subjectivity, Interpellation, Performativity 


\section{INTRODUCCIÓN}

Una de las discusiones centrales en los estudios de género y de mujeres es la que gira alrededor de la constitución de la subjetividad femenina. Desde que Simone de Beauvoir afirmara que "no se nace mujer: llega una a serlo" (De Beauvoir, 1997 [1949]: 15), la idea de una feminidad social y culturalmente construida ha sido planteada de muy diversas maneras. Algunos autores, entre los que se cuenta la propia De Beauvoir, se han preocupado por entender este proceso de la construcción de la subjetividad femenina en diferentes etapas del ciclo de vida. Ello implica asumir que el género y la sexualidad en una cultura se transforman y se hacen significativos a través de las intersecciones con otras categorías, tales como la edad (Eckert, 2003; Biggs, 2004; Hauge, 2009; Nikander, 2009).

La adolescencia ha sido considerada una etapa crucial para analizar estas intersecciones, debido a que es precisamente en esta etapa cuando emerge la posibilidad discursiva de vincular explícitamente el género con la sexualidad, lo cual trae consigo importantes cambios en las demandas sociales y en las opciones posibles para la actuación de los cuerpos (Eckert, 2003; Hauge, 2009; Ringrose, 2011). En la literatura latinoamericana, sin embargo, cuando se aborda esa relación entre la adolescencia y la sexualidad, se destaca generalmente su dimensión problemática, sobre todo en investigaciones centradas en temas como el embarazo no deseado y las enfermedades de transmisión sexual (Stern, 2007; Tuñón y Eroza, 2001); sin prestársele mucha atención a los procesos de transformación subjetiva mediante los cuales la sexualidad pasa a formar parte de la construcción del género en el paso de la infancia a la adolescencia.

Este artículo se propone contribuir modestamente a cubrir esta brecha, enfocando dicho tránsito entre ambas etapas de crecimiento desde los mecanismos de constitución subjetiva que lo hacen posible. Mi interés fundamental es retomar algunos de los conceptos e ideas sobre la construcción discursiva de las subjetividades de género desarrolladas por Judith Butler, para mostrar cómo los discursos que circulan en el contexto mexicano sobre el tránsito a la adolescencia ofrecen a las chicas determinadas posiciones de sujeto donde la edad y el género se relacionan también con la clase social一; cómo algunas adolescentes y sus familias se sitúan de manera crítica y reflexiva ante estos discursos y qué prácticas performativas permiten la construcción de nuevas posiciones de sujeto para ellas, a través del manejo discursivo del paso del tiempo y el control de la sexualidad.

Para ello, dedicaré un primer acápite a presentar, a grandes rasgos, la base teórica del análisis, mostrando, en un primer paso, la relación que establece Butler entre algunos conceptos como interpelación, posiciones de sujeto, performatividad y cita, y, en un segundo paso, reinterpretando desde el esquema butleriano el trabajo de otras autoras que analizan procesos tales como la concepción del paso del tiempo (Nikander, 2009) y la incorporación de la sexualidad en la feminidad adolescente (Hauge, 2009). En un segundo apartado me referiré a la celebración de los 15 años como el contexto discursivo predominante en que se le da sentido a la transición femenina hacia la adolescencia en México, en el cual se producen 
complejas intersecciones entre el género, la edad y la clase social. Finalmente, analizaré las formas en que dos familias autodenominadas de clase media de la ciudad de México celebran los 15 años de sus hijas, rechazando las prácticas tradicionales y construyendo alternativas que les resultan más legítimas para facilitar o demorar la transición adolescente.

\section{LA CONSTRUCCIÓN DISCURSIVA DE LOS SUJETOS} SEGÚN BUTLER: COORDENADAS GENERALES

Uno de los pilares filosóficos del pensamiento postestructuralista es la sustitución de la idea cartesiana del sujeto racional y unitario por la concepción de un sujeto fragmentado y constituido desde posiciones múltiples. En este sentido, el concepto de "posiciones de sujeto" resulta clave para la mayoría de los autores que han tomado este enfoque como punto de partida para sus reflexiones. El término se refiere, a grandes rasgos, a las formas en que los individuos se ubican a sí mismos, o son ubicados por los otros, en construcciones discursivas específicas. Esta idea está basada en las reflexiones de Althusser (1974) sobre la interpelación, que es el proceso de ser llamado o aclamado por un discurso en particular, a través del cual el lenguaje construye una posición social para el individuo, convirtiéndolo en un sujeto ideológico. Al aceptar el rol desde el cual se nos llama $-\mathrm{y}$, por tanto, darnos por aludidos-, nos afiliamos a la posición de sujeto que la interpelación ha creado. Los individuos son interpelados o colocados en ciertas posiciones por formas particulares de hablar, y a cada identidad particular desde la cual uno es interpelado están unidas expectativas de comportamiento particulares.
Los discursos siempre designan posiciones para que las personas las ocupen como sujetos y por ello, lo que somos está siempre relacionado con los textos y las narrativas disponibles desde las cuales se nos interpela (Jørgensen y Phillips, 2002).

Para explicar estos procesos de interpelación mediante los cuales los sujetos son generizados al posicionarse en ciertos discursos, Butler ha desarrollado el concepto de "performatividad"(1990; 2002), basándose en una distinción establecida por Austin (2008 [1971]) entre las formas de habla perlocutivas y las ilocutivas o performativas: las primeras son expresiones que simplemente reportan algo, mientras que las segundas materializan lo que está siendo dicho. Ejemplos de declaraciones performativas son las sentencias judiciales, los casamientos, los bautizos y las palabras pronunciadas en ceremonias de inauguración. Según Austin, para que una declaración tenga fuerza performativa, debe ser emitida por la persona designada para hacerlo, en un contexto apropiado; debe adherirse a ciertas convenciones; y debe tomar en cuenta las intenciones del declarante.

Butler (2002) define los actos performativos como formas de habla autoritarias, declaraciones que al ser emitidas, también ejecutan una cierta acción y ejercen un poder vinculante. Ese poder vinculante del sujeto, que autoriza e instala la situación que nombra, no se encuentra en el sujeto, ni en su voluntad, sino en el legado por medio del cual un "acto" contemporáneo emerge en una cadena de convenciones. Así, cuando hay un "yo" que pronuncia o habla, y de esa manera produce un efecto, primero hay un discurso que precede y habilita a ese "yo" y forma en el lenguaje la 
trayectoria restrictiva de su voluntad. La autora sostiene que el sexo y el género siempre son en algún grado performativos, pues los cuerpos nunca son descritos solamente, sino que son constituidos en el propio acto de descripción. Cuando al nacer un bebé el doctor declara "es una niña”, no está simplemente reportando lo que ve, sino que está asignando un sexo y un género a un cuerpo que no puede tener existencia fuera del discurso. De esa forma, la expresión performativa es una interpelación que inicia el proceso de feminización, un proceso basado en diferencias percibidas e impuestas entre hombre y mujer, que están lejos de ser naturales. A partir de ese momento, la niña está obligada, según Butler, a citar las normas sexuales y genéricas para calificar por la condición de sujeto viable dentro de una matriz heterosexual que la interpela (Salih, 2002).

Al hablar de "cita", sin embargo, Butler está complejizando la propia idea de performatividad, apoyándose en la crítica que hace Derrida (1998 [1972]) a Austin cuando este último afirma que las expresiones performativas sólo son exitosas si se mantienen en los límites del contexto y la intención del autor. Derrida plantea que lo que Austin considera una posible debilidad de los actos performativos es de hecho una característica de todos los signos lingüísticos, que son vulnerables a la reapropiación, reiteración y re-citación. Es lo que él llama la iterabilidad esencial de un signo, que no puede ser contenido o acotado por ningún contexto, convención o intención autorial. Según Derrida, los signos pueden ser trasplantados a contextos imprevistos, citados de formas inesperadas y reiterados de maneras que no se corresponden con las intenciones originales del hablante o escritor.
En la caracterización que hace este autor del signo citacional, Butler (2002) ve un potencial para conceptualizar las prácticas subversivas por medio de las cuales los actos performativos del género son citados e injertados en otros contextos, revelando su fracaso intrínseco. A pesar de esto, reconoce que la citación no es necesariamente subversiva y que ciertas desnaturalizaciones de las normas en realidad las refuerzan (Salih, 2002).

Aunque Butler no formula en sus textos la relación entre posiciones de sujeto, interpelación, performatividad y cita como una propuesta analítica clara y cerrada, sino más bien como provocaciones y preguntas abiertas al debate, considero que algunas de las lecturas que propone podrían ser retomadas para pensar los procesos de construcción de la feminidad en la transición subjetiva de la infancia a la adolescencia. Tomar las ideas de esta autora como punto de partida daría pie a preguntarse por las prácticas que permiten salir a las chicas de posiciones de sujeto infantiles y asumir posiciones de sujeto adolescentes, ubicándose o siendo ubicadas de formas particulares con respecto a los discursos sobre la infancia y la adolescencia que las interpelan. También daría la posibilidad de indagar cuáles son los actos performativos que las construyen como adolescentes y en qué convenciones reside la fuerza performativa de dichos actos, así como qué tipo de citas permiten la subversión de las normas que regulan la entrada a la adolescencia mediante la resignificación de esas convenciones.

Algunas investigaciones con base empírica, sin tomar directamente a Butler como referencia, han llevado a cabo análisis acerca de las prácticas discursivas mediante las cuales las subjetividades 
se construyen al transitar de una edad a otra. Un ejemplo es el trabajo de Hauge (2009), quien propone entender la transición social de las chicas entre la infancia y la adolescencia como una transformación de la posición de sujeto "niña”, que está separada de la sexualidad, hacia la constitución de sí mismas como "adolescentes", que implica negociar articulaciones más explícitas entre la sexualidad y el género. Basándose en esta lógica, Hauge (2009) analiza cómo un grupo de chicas en Noruega negocian los discursos que hacen posibles o imposibles ciertas formas de convertirse en una adolescente, y cómo estos procesos de subjetivación las posicionan de acuerdo a discursos imperantes sobre la heterofeminidad. Uno de estos discursos identificados por la autora es el de la "progresión heterosexual", que prescribe expectativas sobre cómo las chicas deben involucrarse paulatinamente en prácticas heterosexuales, comenzando con el interés por el sexo opuesto a cierta distancia, para luego ir aumentando la proximidad física y la intimidad, pasando del tacto y los besos a las relaciones sexuales. Según Hauge, las chicas son forzadas a negociar formas posibles de ser y transformarse a través de las prácticas corporales, independientemente de si reconocen esos discursos o se resisten a ellos (Hauge, 2009).

Otro ejemplo que remite a prácticas performativas en procesos de transición entre etapas de la vida es el trabajo de Nikander (2009), que si bien no aborda el género directamente, ni se enfoca en la adolescencia sino en el proceso de envejecimiento, analiza las prácticas que utilizan algunos sujetos para manejar las nociones de continuidad y cambio personal mediante el habla.
La atención de esta autora se centra en la acción discursiva a través de la cual los significados de la edad, el cambio y la continuidad surgen en la interacción, enfocándose en la construcción dinámica de significados y en las metas que se logran. En su análisis empírico, Nikander identifica un dispositivo discursivo recurrente que denomina "continuidad provisional", por medio del cual los hablantes (finlandeses entrevistados al cumplir 50 años) reconocen ciertos cambios corporales, sociales y psicológicos como algo normal que va a producirse en su vida, pero a la vez se ubican a sí mismos provisionalmente fuera de ese cambio. Lo anterior lo logran contraponiendo en su discurso marcadores temporales como "más adelante" o "en algún momento" para referirse a lo que sucede en general a las personas de su edad, con otros como "todavía", "aún no" o "ahora" para referirse a lo que está sucediendo tanto con ellos como con ellas mismas.

A partir de estos elementos, mi objetivo es mostrar cómo estos dispositivos de la progresión heterosexual y la continuidad provisional, incorporados al marco conceptual de Butler, pueden ser considerados herramientas performativas para la construcción de nuevas posiciones de sujeto en el tránsito de la infancia a la adolescencia en México. Para ello es importante tener en cuenta, en primer lugar, que dichas posiciones de sujeto no surgen de la nada ni son abstractas y universales, sino que están condicionadas por los discursos específicos que circulan en el ámbito social acerca de dichos procesos de transición. Como señalaba más arriba, en el caso mexicano estos discursos están relacionados fundamentalmente con la celebración 
de los 15 años, por ser este el momento en que se reconoce socialmente que tiene lugar el tránsito a la adolescencia femenina. El análisis de dichas prácticas performativas debe comenzar, entonces, por una revisión de esos significados que se les ha atribuido a tales celebraciones.

\section{LOS 15 AÑOS EN MÉXICO}

El acercamiento y la mirada a los 15 años como un ritual cuya función es permitir o facilitar procesos de "constitución" o "producción" de subjetividades relacionadas con el paso de una etapa a otra en la trayectoria de vida, ha estado presente en varias investigaciones (Nieto, 2001; Ruiz, 2001). Aunque sus autores no aclaran qué están entendiendo por "construcción subjetiva", queda implícita su asociación con los efectos de cierto simbolismo ritual que se despliega en las fiestas.

Ruiz (2001), por ejemplo, indaga los significados de la fiesta de 15 años en la ciudad de Guadalajara, los mensajes que la misma intenta hacer llegar a "la niña que se vuelve mujer", y los posibles beneficios y limitaciones que la celebración representa. Según Ruiz, aunque la fiesta de 15 años se lleva a cabo con variaciones en los detalles, repite sin falta algunos elementos que tienen especial significación en el simbolismo ritual, como la misa católica, el baile de la chica con el padre y la entrega simbólica a otros hombres jóvenes. La autora llama la atención respecto a que en las celebraciones no está presente ningún símbolo que haga referencia a la posibilidad de que las mujeres ocupen lugares públicos en la sociedad, y señala que en este sentido, el ritual parece sugerir actitudes pasivas a las chicas y conlleva el riesgo de que éstas puedan sentir que su ámbito de desarrollo se circunscribe a la esfera doméstica.

Aunque esta autora no utiliza el concepto de performatividad, su análisis se basa en atribuir al ritual un poder performativo, donde el tipo de prácticas que son representadas (el baile con el padre, la entrega a otros hombres, etc.) construirá formas específicas de subjetividad, al sugerir actitudes y hacer referencia a lugares — que podrían entenderse como posiciones de sujeto- disponibles para ser ocupados por las quinceañeras. Esta interpretación se acerca un poco a la concepción austiniana sobre la eficacia de lo performativo como algo que está contenido en la forma y el contexto en que se ejecuta el acto ritual, que interpela a las quinceañeras a situarse en el discurso de la feminidad normativa, canónica y tradicional; ellas, como señala Feixa (1998), aceptan su lugar en la sociedad como jóvenes inocentes, sumisas y listas para el matrimonio. Sin embargo, estas y otras investigaciones han mostrado que este tipo de prácticas no son la única manera de asociar la transición adolescente con el momento de cumplir 15 años.

El propio trabajo de Ruiz (2001) señala que en medios menos tradicionales muchas chicas rechazan la celebración, prefiriendo una fiesta juvenil o un viaje que podría tener la carga simbólica de abrirse a nuevos horizontes. Palencia y Gruel (2006) entienden la fiesta de 15 años como un ritual que conduce a las jóvenes a diversos marcos de referencia, el cual coloca la acción de las chicas en una posición pertinente para intervenir en las representaciones sobre su propia sexualidad y sobre la institución familiar, abriendo posibilidades para la autodeterminación. Meira (2009), al igual que Ruiz 
(2001), analiza la función de diferentes símbolos presentes en las fiestas de 15 años, como el vestido, el ramo, el último juguete, los chambelanes, la dama de honor, la coronación, las invitaciones y el pastel. A partir de ahí, concluye que el ritual de la quinceañera es un ejemplo de discurso canónico tradicional sobre el deber ser de la mujer, que sirve para seguir marcando, consagrando y haciendo visibles las diferencias entre los sexos; pero por otra parte, reconoce que ese discurso canónico sobre el deber ser muchas veces se deconstruye, y que cada mujer tiene la posibilidad de seguir con lo conocido, o "lanzarse a la aventura de la vida".

En estos textos, los discursos alternativos que rechazan la tradición se atribuyen a las clases medias y altas de la sociedad mexicana, mientras que las prácticas performativas que reproducen el sentido tradicional de las celebraciones, se asocian con las clases más pobres, bajas o populares. Algunos autores establecen esta distinción de manera relacional, como Nieto (2001), quien señala que al apropiarse de este ritual, los grupos populares intentan resolver simbólicamente la desigualdad presente en la sociedad; mientras que para quienes lo dejan, tal abandono significa mantener la diferenciación social intacta. Sarricolea y Ortega (2009) también plantean que en Tizimín, Yucatán, los sectores populares incorporan a través de estas fiestas elementos de prestigio y distinción social, mediante los cuales buscan acercarse a la urbanización y modernidad que perciben en las clases altas, y que el tipo de mujer que las quinceañeras aprenden a ser, muchas veces escapa de su realidad inmediata al relacionarse con cánones puramente elitistas. Del mismo modo, para Feixa (1998), los 15 años son un claro ejemplo de apropiación y reelaboración cultural por parte de las clases subalternas de ritos pertenecientes a las élites.

A partir de lo anterior, la existencia de discursos alternativos para las quinceañeras podría interpretarse como posibles resistencias o subversiones a las normas de género que son representadas en la fiesta típica; es decir, como prácticas que citan la norma de celebrar los 15 años, pero la saturan con otras formas y otros contenidos. Los actos citacionales que se alejan de la norma, sin embargo, podrían funcionar simultáneamente como actos performativos de construcción de subjetividades de clase media y alta, que rechazan la convención de la fiesta típica justamente porque la relacionan con las clases bajas o populares. Muchas son las interrogantes que quedan abiertas, sin embargo, en relación con estas prácticas citacionales y los procesos de construcción subjetiva que a través de ellas tienen lugar: ¿cómo la celebración de los 15 años interpela a las chicas que se consideran de clase media o alta, y a sus familias, con respecto a la transición de la infancia a la adolescencia? ¿Por medio de qué mecanismos discursivos se rechaza o se acepta esa interpelación? ¿Cómo se reinterpretan las normas acerca de la transición a la adolescencia a través de opciones alternativas de celebración? ¿Qué actos performativos autorizan e instalan entonces el tránsito de una posición de sujeto infantil a una posición de sujeto adolescente? ¿Funcionan aquí los dispositivos discursivos de la progresión heterosexual y la continuidad provisional?

Para intentar dar respuesta a estas preguntas, presentaré a continuación dos estudios de caso que permitirán examinar más de cerca las prácticas 
citacionales que despliegan algunas familias al celebrar los 15 años de sus hijas, sin reproducir los elementos del simbolismo ritual presentes en la fiesta típica.

\section{EL VIAJE FAMILIAR} Y LA TRANSICIÓN POSTERGADA

La primera quinceañera de este estudio se llama Carla y es la hija mayor de Mariana y de Roberto; Carla tiene un hermano menor, que se llama como su padre. La familia vive en un pequeño departamento en una unidad habitacional de la colonia Jardín Balbuena, en la ciudad de México. Mariana, para quien éste es su primer matrimonio, es ama de casa; Roberto, quien tiene tres hijas de un anterior matrimonio, es médico pediatra.

La referencia a la celebración de los 15 años, como la significación de la etapa que supuestamente representa en la vida de la mujer, es la primera explicación que me da Carla cuando le pregunto por qué ella cree que se celebran los 15 años. Sobre esto me dice: "se celebran porque ya dejamos de ser niñas, estamos como se dice: en la pre-adultez. Se dice que llegamos a las 15 primaveras, así es como se les dice."

Su madre, Mariana, hace referencia a ese mismo discurso del evento de transición, pero no se lo apropia. Lo cita, más bien, como algo remoto y accesible a la vez, como una representación que sabe que circula, pero que ni la comparte, ni renuncia totalmente a la posibilidad de hacer uso de ella. Esa ambigüedad se ve muy claramente cuando dice que celebrar los 15 años significa "que presentas en sociedad a tu hija, que llega el momento en que tu hija ya no es una niña, ya es una señorita, y que la vas a presentar ante sociedad, socialmente ya está en otro estatus, ¿no? Ese es el significado que nosotros le hemos... es el que se hace, por eso. Pero yo no..." Aquí, Mariana se debate entre el "nosotros", que establece y reproduce el significado de la transición social, y el "yo", que se resiste a aceptar ese significado.

Esas dudas acerca del sentido de transición asociado a las fiestas de 15 años están relacionadas con una actitud muy crítica respecto a la forma de celebrar, que tanto ella como Carla reconocen como típica. Este patrón típico me lo describe Carla de la siguiente manera:

Lo que nunca debe faltar es el vals, que la quinceañera lo baila con su papá o su hermano. Hay dos rituales opcionales: uno es el del último juguete y el otro es el de los zapatos. El último juguete es un juguete que se le da a la quinceañera para recordar que ya no vas a ser niña; y el de los zapatos es que en la fiesta traes zapatos bajitos y en un momento de la fiesta te los cambian por zapatos de tacón.

Al respecto, Mariana me comenta: "Es que la celebración típica era esa, con todos esos rituales, y ha ido cambiando porque las costumbres si no cambian mueren, aunque sin perder la tradición. Los que generalmente todavía hacen todo eso son los niveles más bajos, la sociedad lo considera de mal gusto."

Con esta enunciación, Mariana está empleando el "gusto" como un recurso simbólico de segmentación social, relacionando el mal gusto con las clases bajas y la realización de la fiesta típica. Este es un mecanismo mediante el cual se deslegitima la supuesta norma, asociada a la forma 
típica de celebrar la transición a la adolescencia, que es atribuida a una clase social a la que no se desea pertenecer. Otra distinción enunciada por ella es la territorial, establecida entre los contextos urbanos y rurales: "si te vas a un pueblo fuera del DF, a las comunidades, es muy diferente. Ahí invitan a todo el pueblo, las fiestas duran dos o tres días..., aquí no, apenas son de un rato; y a veces ni se hace la fiesta, se usa que las chicas vayan a un antro a celebrar sus 15 años ahí con sus amigos". Al decir esto, Mariana establece una relación inversa entre la urbanización y la complejidad y extensión de la fiesta.

Otro aspecto presente en la representación que tienen Carla y Mariana sobre la fiesta típica es su forma de financiamiento, la cual se produce mediante "padrinos". En la entrevista con Carla, por ejemplo, en medio de su descripción, me dice: "a algunas las apadrinan, y están los padrinos de la música, los de las fotos, los del pastel, los del vestido, el salón, de todo..." Yo le pregunto qué significa que las apadrinan, y me responde: "que son los que les regalan el vestido o la música, o cualquier otra cosa de la fiesta."

Esta estrategia de compadrazgos es negada rotundamente tanto por Mariana como por Roberto como alternativa para financiar la celebración de Carla. Al respecto Mariana afirma: "Muchas amistades nos han dicho: 'Ay, nosotros les apoyamos' No. 'Yo le compro su vestido, yo le compro su...' No. No es así. Dice mucha gente que somos orgullosos; yo digo que no es un orgullo. Te juro que no es orgullo. Yo soy de las personas de que para mí eso es educación. Si no tienes para dar y compartir, no tienes por qué hacer nada. ¿Tienes? Hazlo; ¿no? No se hace." Roberto comparte esta misma postura:
[...] Nosotros siempre hemos sido muy apegados a los otros familiares. Ahorita el que más y el que menos se me ha acercado: 'oye, ¿y qué va a hacer Carla para su cumpleaños? Yo le pongo el vestido, yo le pongo el pastel, yo le pongo esto, yo le pongo lo otro.' Y hasta vecinos ya. Y no es por orgullo ni soberbia, pero no debe ser así. Porque si se lo voy a hacer, yo se lo voy a hacer. Y no por eso soy vanidoso ni soberbio, y les agradezco a todos los que se han ofrecido, pero el compromiso es mío [...]

A partir de estos fragmentos, podemos ver que esta familia concibe los compadrazgos como una acción cuyo significado se contrapone a algunos de sus valores, lo cual la convierte en un vínculo social con personas externas a la familia, que es inaceptable en los marcos de una celebración. Es vista como una petición; y es esta idea de necesitar del otro, de solicitar apoyo del otro, la que es rechazada y colocada fuera de los marcos de "la buena educación". Ante la imposibilidad de solicitar y aceptar ayuda externa para financiar la fiesta, el gasto que implicaría hacerla por cuenta propia se vuelve motivo de reflexión y negociación en la familia: “A mí, la verdad, como dices, tanto dinero para una noche... Es que no son cinco mil, diez mil, veinte mil pesos... y que al otro día como si no pasara nada... Yo no puedo", comenta Mariana visiblemente angustiada. "Depende de cuán importante sea para la gente, ¿no?”, le pregunto; y ella contesta: “[...] ¡Te marca! Claro. Pero yo digo que cuando se hacen los 15 años... yo ahorita con Carla estoy sintiendo que si se hacen (todavía estamos que si te lo hacemos, que si no te lo hacemos)... A nosotros, por dinero. Porque se va elevando la suma. Entonces nosotros hasta 
unas tres semanas más sabemos si se hace o no se hace."

Al intentar explicarme la facilidad con que Carla cambiaba de idea sobre lo que quería hacer por sus 15 años, como justificación de su posible renuncia a la fiesta, Mariana me cuenta:

Y es que ella no quería. Le preguntamos varias veces, hace meses, y ella: 'yo no' ‘De veras, Carla?' 'Yo no.' $\mathrm{Y}$ cuando te dice eso, tú te confías, y si no echas al marrano, te lo gastas. Y te sale, a los dos meses antes: ‘siempre sí'... ¡No, mi reina!... Mira, la cuestión primer es tener el dinero, ya teniendo el dinero se define. Primero la materia prima [se ríe]. No estamos preocupados por eso, eh. No, porque de cualquier manera ella convoca a sus amistades, se le renta una carpa abajo, se le manda a pedir lo que quiera, y que se esté abajo con sus cuates todo el tiempo en el cotorreo. O sea, a finales de cuenta ella se va a divertir. No va a pasar en cero. Pero primero es tener la materia prima y después ver.

Esa idea de "no va a pasar en cero", como síntesis de todos los esfuerzos que la familia está haciendo para poder festejar, indica el peso discursivo del momento específico de los 15 años como algo celebrable, sin importar cómo se celebre. ¿Cómo se explica esta postura en una familia que rechaza explícitamente la reproducción del patrón típico de las fiestas de 15 años? La respuesta es la existencia de discursos alternativos que dejan intacto el imperativo de celebrar, aunque no se acepte la forma típica y tradicional. De esa forma, no hay una única manera de hacerlo, sino muchas variantes posibles. Con esto se matiza la interpelación de este campo discursivo hacia la familia, pues no se les plantea una situación dicotómica de "lo tomas o lo dejas", sino de "cómo lo haces", donde están convocados y convocadas a situarse como consumidores. Esta variedad de opciones legítimas de celebración, por tanto, garantiza a esta familia la posibilidad de encontrar alguna opción viable, alguna forma de "citar" la norma sin reproducirla de la manera tradicional: "a ella se le dará su gustito", asegura Mariana, y Roberto la apoya: "se le da su gusto".

Una práctica alternativa a la fiesta, que se contempla como posibilidad, es viajar a Europa para pasar su cumpleaños con una de sus hermanas, quien está haciendo una estancia de investigación.

Con este tema comenzó mi segunda entrevista con Carla:

Yo: Bueno, cuéntame: ¿cómo andan los planes de celebrar tus 15 años?

Carla: Pues hay algunos cambios en los planes. Ahora estamos viendo la posibilidad de irme a Europa con Ariadna.

Yo: ¿Y de qué depende que te vayas?

Carla: Depende... de dinero [se ríe], depende de que me den permiso mis papás...

Yo: Y entonces, ¿ya no quieres hacer fiesta, o qué?

Carla: Es que... todo iba bien; pero hasta que me dice Ariadna como que me entró la cosquillita, ¿no? Y dije: no, pues estaría súper padrísimo, imagínate... yo sí, yo sí quiero ir.

Sin embargo, en cuanto sale el asunto del viaje a Europa en la conversación con Mariana, esta deja bien clara su postura al respecto: "tus 15 años, se te festejen o no se te festejen, tienes que estar con tus papás. No tienes que estar fuera. Eso se festeja, aunque sea un pastel aquí los cuatro, pero con tus padres. Los 15 años no tienes por qué estar lejos 
de los papás. Eso sí está claro.” Dirigiéndose a mí, reafirma lo que acaba de decir: "sola no se va a un viaje tan largo; mi autorización no la tiene [...] Puede ir después. Sus 15 años y ese preparativo de 15 ... o sea, preparativo a lo mejor no social; pero el tiempo de los 15 , aquí con sus papás."

Más adelante me explica con más detalle su punto de vista:

Yo digo que no. Y no es capricho, no es egoísmo, no es nada de eso. Yo le tengo una buena razón, que es que ese tiempo es para compartirlo con nosotros. Esa es la razón mía... Ella todavía es una menor de edad y todavía tiene que estar bajo las reglas y bajo el techo de sus padres... Lo importante es que, haga lo que haga, va a ser un día especial. Yo pienso que uno no debe basar la felicidad en un evento social. No puedes ser feliz o infeliz por un evento social. Y a Europa que se vaya después.

Aquí resulta muy interesante cómo la representación de Carla como sujeto es condensada para Mariana en el significante "menor de edad", mediante el cual la construcción discursiva de "los 15 años como evento social" se subordina a la construcción discursiva de "el tiempo de los 15 años", donde el vínculo social más importante es "estar bajo las reglas y el techo de sus papás".

Roberto, sin embargo, no piensa lo mismo:

A mí me gustaría que ella conociera el mundo. Que viera cómo es la gente en otros lugares, que forme conceptos propios, que no le platiquen, sino que lo vea por ella misma. Porque en esa edad todo es muy importante; todo lo que tú percibes se te queda grabado para tu futuro. Y en un momento dado, dices: 'esto ya lo viví, ya lo he visto.' No es por ser presuntuosos, porque le pregunten: 'Ah, ¿qué hiciste por tus 15 años?' 'Fui a Europa'; no, no es eso; sino que ahorita, con tanta información que hay, sería muy importante para ella conocer, ver qué hay... Me parece bonito, es interesante para ella poder viajar y ver todas las cosas que hay fuera de tu país, de tu ciudad. Eso te forma un concepto más amplio de la vida y eso te estimula para ya en lo adelante quererlo hacer ya por tus propios medios. Yo difiero mucho en ese sentido.

Aquí hay una enunciación de los procesos de construcción subjetiva asociados a esta etapa de la vida de Carla muy diferente a la que hace Mariana. En lugar de enunciar a su hija como una menor de edad, que debe estar "bajo el techo de los padres", Roberto construye esta etapa proyectada hacia el futuro, hacia el mundo exterior; como un momento ideal para tener nuevas experiencias y formarse conceptos propios. ¿Cómo se resuelve este conflicto? Mariana ejerce su poder de madre para imponer su decisión, pues según ella, aunque Roberto está en contra, es ella quien decide:

Yo: ¿Y el papá qué piensa de eso?

Mariana: Él sí la quiere mandar, pero yo no.

Yo: ¿Entonces están en la discusión?

Mariana: No. No hay discusión alguna. Si no firmo yo, no sale del país. Sí, así es. Porque debe de estar con nosotros en ese tiempo de su natalicio.

Esta intervención de Mariana desde su poder de madre constituye un acto de habla performativo, de los referidos por Butler. Cuando Mariana dice, por ejemplo: "mi autorización no la tiene" o "yo digo que no", está realizando las acciones de negarle la autorización a Carla y decir que no respectivamente. De esta forma la construye como una "menor de edad", que todavía "debe estar bajo las reglas y bajo 
el techo de sus padres" en lugar de "viajar y ver todas las cosas que hay fuera de su país y de su ciudad" para "formarse un concepto más amplio de la vida", como quisiera su papá. En este caso, las oraciones pronunciadas por la madre están realizando una acción y además le confieren un poder vinculante a la acción realizada, aunque en este caso el vínculo no sea otro que mantener a Carla en el mismo sistema de relaciones sociales en donde se encontraba.

El discurso que en este caso precede al yo para establecer la trayectoria restrictiva de su voluntad, como señala Butler, es el discurso de los 15 años como momento de transición que interpela a los padres para que permitan y propicien cambios en la posición social de sus hijas; pero aquí la madre, como figura de poder, en lugar de instaurar algo nuevo, lo que hace es reafirmar prácticamente la misma posición de dependencia que había en la infancia de Carla. Ese poder de conferir -o no conferir- de la madre, reside también, según Butler (2002) y Austin (2008 [1971]), en la invocación de una convención. Ello es explícito en su discurso cuando dice que aunque el padre no esté de acuerdo, no hay discusión, porque es ella quien tiene la potestad legal para autorizar o no la salida de su hija del país. El "yo" de Mariana ("yo digo que no") produce un efecto discursivo, porque primero hay un discurso sobre las funciones y el poder de la madre en la familia, que precede y habilita a ese "yo" para realizar ese tipo de enunciaciones performativas.

Al calificar a Carla como menor de edad, la transición a la adolescencia es postergada, y el acceso a las nuevas formas de actuar el cuerpo relacionadas con esta etapa, de cierta forma también es diferido. Un ejemplo en el que esto se pone de manifiesto es la siguiente enunciación donde la propia Carla se ubica discursivamente ante las relaciones de noviazgo:

\begin{abstract}
No es de que haya tenido, sino de que 'ay, ese chavo está bonito', o 'me gusta'; pero novio, novio ya en sí, no. No sé, como que ahorita no me interesa tanto eso. El novio cuando llegue llegará, y si no, pues no, y... No estoy: "no tengo novio, ay, ya voy a tener novio'... No, a mí me gusta, ya sabes, salir con las amigas y estar así, en la fiesta y todo. Ahorita no lo veo como algo importante, ni que lo necesite. O sea, sí hay compañeros de la escuela que los veo y digo: 'me atrae, me atrae'; pero no así para ya..., 'no ya, quiero que andemos, ya, ahorita', son cosas que pasan, pero ya más adelante llegará.
\end{abstract}

Aquí, Carla está haciendo uso de la estructura discursiva de la continuidad provisional (Nikander, 2009) a través de la cual reconoce ciertos cambios como una norma, pero al mismo tiempo se sitúa a sí misma temporalmente fuera de ellos. Esto lo logra mediante la contraposición entre el "ahorita" y el "algún día". Carla sabe que el novio "algún día llegará", pero "ahorita no le interesa ni lo necesita". De ese modo, se mantiene fuera del universo hetero-femenino donde se establecen las relaciones de noviazgo. Tanto Mariana como Roberto se refieren de un modo similar al acceso de Carla a las relaciones de pareja. Roberto lo explica de esta manera: “[...] se le ha planteado mucho eso, ¿no? 'Mira, Carla, no es la edad todavía. Ya tendrás tiempo, edad, ahorita estás en el proceso de la escuela'... Yo les digo a los novios quitatiempo. Ahorita no es momento para un quitatiempo. Porque te distrae tanto en tus actividades escolares como de casa. Entonces 
ya llegará el tiempo en que pueda ser eso, pero ahorita sí somos muy tajantes."

En cuanto a la celebración de los 15 años, después de decidir que Carla no viajaría a Europa, y saber finalmente cuánto dinero tenían disponible, Roberto y Mariana le dieron varias opciones para que ella eligiera qué quería hacer. Mariana me cuenta:

Ya finalmente para el cumpleaños de Carla tenemos varias opciones, le dijimos a Carla: rentamos una carpa para tu cumpleaños, invitas a tus amigos, unas pizzas, un DJ, te la pasas cotorreando sin que interfiera nadie, o nos vamos a Cuernavaca el fin de semana, te la pasas nadando, te llevas dos amigas que invites; o nos vamos a aceptar la invitación de una amiga que acaba de salir de aquí a Querétaro y que nos ofrecen estar allá y llevarla a pasear a varios lados. Le dijimos a Carla: escoge. Y ella decidió ir a Querétaro y a Guanajuato, a varias partes de la zona, cerquita; entonces nos vamos a pasar todo el fin de semana que cae su cumpleaños, allá; probablemente en casa de la amiga le compremos el pastel.

Con esta variante de celebración, logran conciliarse bastante los diferentes intereses planteados en torno a la celebración: hacen un viaje, que aunque no es internacional, tiene algunas implicaciones para la familia, como práctica de clase media que les permite evitar la celebración tradicional; pasan todos juntos "el tiempo de los 15 años", y también socializan más allá de los marcos de la familia, al compartir la celebración con sus amigos de Querétaro. El análisis de este caso muestra cómo se construye en esta familia la celebración de 15 años como una acción vinculante, con la cual se resiste de alguna manera la norma de facilitar a través de esta celebración la transición subjetiva a la adolescencia femenina. Dicha celebración es usada también por la familia para desafiar simbólicamente procesos de movilidad social descendente, desplegando prácticas discursivas que les permiten mantener una construcción subjetiva de clase media.

\section{LA FIESTA TEMÁTICA Y LA TRANSICIÓN REINVENTADA}

La segunda quinceañera entrevistada es Yadira, quien vive con su mamá, Diana, y con Alfredo, el esposo de ésta; habitan en un departamento pequeño, en una unidad de la colonia Morelos, muy cerca del centro de la ciudad de México. Diana y Alfredo son sociólogos. Yadira estudia el bachillerato en un Centro de Educación Artística (CEDART), donde aspira a especializarse en danza.

La idea que transmite Yadira sobre lo que representan los 15 años como etapa en la vida de la mujer es bastante parecida a la de Carla: "bueno, se supone que en la antigüedad, los 15 años eran para marcar el paso de una joven que era así, que pasaba a ser ya una mujer, por decir. O sea, era una niña, aún se supone, adolescente, y al cumplir los 15 años, al momento en que la coronaban, según esto, era cuando ya pasaba a ser una mujer."

Diana y Alfredo, por su parte, enuncian el significado de estas celebraciones en forma de análisis sociológico, como en el siguiente comentario de Diana: “[...] los 15 años sí son un parteaguas en la vida de las mujeres, no tanto en los hombres; en los hombres yo creo que se da más como a los $18 \ldots$ Sí es muy significativo como esa parte de que los 15 años en las mujeres es que ya no eres una niña, ya eres una adolescente, ya es fértil, ya puede tener hijos, ya puede casarse". En sus observaciones, 
Diana establece una diferencia muy clara entre la narrativa social que circula acerca del significado de los 15 años, y los efectos prácticos de este evento en la vida de las personas, asumiendo que aunque ambas cuestiones estén relacionadas, no son idénticas. Esto se aprecia en el siguiente comentario: "Después de los 15, las mujeres tienen otro tipo de libertades. Simbólicamente hablando, porque en realidad no las tienen, o las tienen desde antes, pero simbólicamente hablando yo lo veo así'. Con esto, relativiza el carácter performativo de este evento con respecto a la transición hacia la adolescencia.

Al igual que Carla, Yadira identifica claramente un patrón de fiesta típica de 15 años:

A los 15 años que yo he ido, supuestamente primero tienen que ir a la iglesia a hacer su misa. Así de que 'ay, mis 15 años, qué sé yo qué' y luego van y hacen una fiesta en donde se supone que a la chava esa la coronan y le dan su último juguete. Así, un osito, una muñequita o algo así. Y luego baila un vals ella solita, luego un vals familiar y luego la coreografía, la que ella quiera... y ya, y una fiesta así, en grande.

Después de esta descripción, me dice: "bueno, a mí, la verdad esa forma no me gusta. Es así de ¡aghhh!, ¡qué empalagoso!”. Después intenta explicarme un poco mejor: "no me desagrada la idea de hacer una fiesta; me desagrada la idea de tener que llevar un vestido y la corona, y el juguete, y la... no me gusta". Luego me cuenta lo que ella quiere hacer por sus 15 años:

Es que primero mis abuelitos de parte de mi papá, hostigosísimos, que si no iba a querer fiesta, y yo: ‘no'... ¡Y no se han cansado!, todavía me vienen a ver, y ‘¿para cuándo tus 15?’... Pero luego empecé a ver un programa en MTV que se llama "Quiero mis 15", y "Sweet Sixteen" y pues dije: 'ah, pues está padre'. Y luego empecé a ir a fiestas de 15 años, y no, pues está padre, pero es que es muy empalagoso para mí, es muy..., es como mucho para mi estilo, para mi forma de ser y mi forma de pensar. Y luego ya vi un documental, más o menos, de circo, del cirque du soleil, o algo así, y pues dije: 'ay, si hago una fiesta así sencilla, que el tema sea algo así como circo, y que nada más vayan así puros amigos.'

Lo curioso aquí es que Yadira se resiste a la interpelación de la celebración de 15 años cuando está asociada a la familia extensa tradicional, representada por sus abuelos; pero sí se siente convocada por un referente distinto que viene de los medios de comunicación. Aquí el llamado cultural es explícito en el propio título de uno de los programas: "Quiero mis 15"; y el mensaje tiene en Yadira el efecto buscado, porque ella termina queriendo sus 15 al ver el programa. El otro referente que menciona son las fiestas de sus amigas, que al parecer sí se ajustan al patrón típico. Estas construcciones de celebración que le llegan desde afuera, sin embargo, son para ella referentes ambivalentes, pues en lugar de aceptarlas completamente, se cuestiona qué tanto tienen que ver con "su forma de ser" o "su forma de pensar", al imaginar cómo será su propio festejo:

A mi estilo, pues... porque por ejemplo, no quiero nada de vals, ni de... ¡a lo mejor bailar sí, eso todavía lo sigo pensando! Y que no haya menú ni nada así, sino puros bocadillos: una tostada con atún, una torta, unos tacos. Yo tengo planeado así como que sea una fiesta de circo, y que vayan disfrazados de circo. Porque en todas las fiestas de 15 van así vestidos con el tacón, mis amigas llevan taconsísimos, que digo: 'vas a bailar, o sea, no vas a un desfile de modas'. O sea, yo soy enemiga de 
los tacones porque no me gustan, y entonces pues así, sin vestidos ni nada, nada más con un disfraz o algo así.

Esta utilización estratégica de la fiesta de 15 años para la construcción de un estilo propio es enunciada verbalmente a través de la construcción “está padre, pero...", donde el "pero" indica que al ubicarse en algún discurso, no lo acepta tal y como ya viene construido. Yadira no le pone nombre a su estilo, pero muestra que éste no incluye vals, ni menú, ni tacones, ni vestido, sino disfraces y bocadillos. Con ello, está rechazando el uso de ciertos símbolos de las fiestas típicas de 15 años asociados a la heterofeminidad, como los tacones y los vestidos; y sustituyéndolos por otros símbolos como los disfraces, con lo cual está ensayando una manera distinta de representar su feminidad adolescente.

Esta centralidad del yo, y esta enunciación del estilo propio como un discurso recurrente en Yadira, aparecen también en las narrativas de Diana, asociadas al proceso de toma de decisiones sobre la celebración. En la última entrevista, tres días antes de la fiesta, Diana me dice al respecto: "entonces le dije a Alfredo: 'según Yadira, no quería una fiesta'; o sea, la armó como ella la imaginó desde un principio, pero nunca lo dijo. O sea, fue un plan como macabro, que nos fue llevando a hacer algo que pensábamos que no iba a ser; y al final sí lo va a hacer."

El anterior enunciado de Diana sugiere que, si bien desde el principio le dieron a Yadira la posibilidad de decidir lo que quería hacer, había cierta resistencia por parte de ellos a organizar una fiesta, ante lo cual Yadira tuvo que utilizar estrategias muy sutiles de persuasión. Esto es abordado más claramente por Diana en otros momentos de la entrevista, cuando asocia su resistencia a los gastos que implicaba el festejo: "nosotros fuimos los que le dijimos que una fiesta sencilla sí le podíamos hacer. Una fiesta lujosa pues no, porque, aparte de que tenía que ser con tiempo, a mí sí se me hace como un desperdicio de dinero. Yo siento que podemos gastar el dinero en otras cosas que gastarlo en una fiesta de 15". La solución que aparece en la narración de Diana ante este conflicto entre no gastar mucho y hacer una fiesta al estilo de Yadira — que ya se va perfilando como algo más complejo que una simple reunión de adolescentes-, es recurrir a las redes de amigos:

[...] entonces, como la mamá de mi amigo se dedica a organizar fiestas y eso... entonces le dijimos, y me dice: 'pues deja le pregunto al muchacho éste, pero le voy a decir que es mi sobrina, para que nos haga un súper descuento'. Entonces no nos vamos a gastar más de diez mil pesos en la fiesta. Pero como Yadira sabe que al final vamos a terminar gastando algo que no queríamos, me dice: 'es que... quiero un vestido, pero me lo voy a hacer yo’; y yo: ‘Ajá, Yadira: a ver, ¿cuál te vas a hacer?’ Y ya lo veo y le digo: ‘Ajá, no manches. Eso ni tú ni yo lo vamos a hacer'. Y me mira y me dice: 'es que si no va a salir muy caro'. Y yo así: ‘quién hace vestidos, quién hace vestidos?’ Entonces le hablé a la mamá de otro amigo que me acordé que es maestra de costura, y sí, la señora se movió y me consiguió ya el vestido en dos días, creo, tres días; lo están haciendo. Todavía no nos lo entregan, pero ya está casi el vestido, ya lo fuimos a ver. Pero pues obviamente es muy barato, porque sus alumnas lo están haciendo. 
Aquí vemos una construcción discursiva de las redes sociales muy diferente a la del primer caso, donde la posición de anfitriones era construida tan rígidamente que les impedía buscar mecanismos de apoyo. En este segundo caso, no hay ningún sentido de vergüenza ni de fracaso asociado a la activación de estas redes; sino que este acto se enuncia como parte del propio proceso de deconstrucción de las formalidades usado estratégicamente por Yadira y apoyado por Diana y Alfredo, para reinventar la fiesta de 15 años. Diana presenta las redes familiares y sociales que se articulan alrededor de los 15 años de Yadira, dotadas de un sentido de identificación alrededor de nociones como la "locura" y la "diversión":

Yadira, loca; nosotros, que le seguimos la corriente, pues todavía somos sus papás; nuestros amigos, pues porque son nuestros amigos y nos siguen la corriente, y por eso también se van a disfrazar los pocos que irán; pero lo peor de todo es que dos mamás de amigos: una de ellas nos va a hacer el vestido, porque es costurera; y la otra es la que nos organizó la fiesta, y haz de cuenta que cuando le dijimos que iba a ser de circo la fiesta, nos dijo: 'les consigo un camello' [risas]. 'No, señora, gracias'. Y ella, que si hacemos una carpa, y que no sé qué; y le digo, 'nosotros locos, nuestros amigos que nos siguen la corriente, y las mamás de nuestros amigos que también nos siguen la corriente, ¿adónde vamos a llegar?' Pero la verdad es que yo me divierto mucho... o sea, yo con Yadira me divierto, con sus ideas y todo [...]

Esta combinación de diversión y locura refuerza la idea de que la identidad familiar y la subjetividad de Yadira se construyen sobre la base de posiciones, compartidas por el grupo social, que valoran lo alternativo, la informalidad, la libertad y la autodeterminación. La construcción discursiva de Yadira como sujeto autónomo es enunciada también por parte de sus padres en otras conversaciones que no se centran en las celebraciones de 15 años. Al respecto, Alfredo señala:

Yadira sabe decidir muy bien, cosa que yo no hacía a esa edad. Hoy por hoy, Yadira dice: ‘no quiero', y creo que esta libertad que le hemos dado es para decirle: 'tú en la casa eres una más, o sea, no porque eres la más pequeña, no tienes derecho a decidir'. Y hoy por hoy, decide muy bien y defiende su punto de vista. Cuando dice no quiero, creo que nosotros hemos sido muy respetuosos del no quiero.

Este testimonio recuerda bastante al "yo habilitado por el discurso para ejercer su voluntad", del cual habla Butler (2002): Alfredo y Diana, al respetar el "no quiero", están dotando a Yadira de una capacidad de realizar enunciaciones performativas, construyendo realidades al nombrarlas. Cuando ella dice que no quiere algo, está realizando la situación en la que se niega, y esa situación es respetada y legitimada discursivamente por sus padres. Diana reafirma esto cuando dice:

Yo siempre le he dicho: 'mira, yo me dejé influenciar mucho por personas; ¿por qué?, porque nunca me enseñaron a decidir ni a decir que no, ni nada. Entonces, tú sí sabes decir que no, y sabes decir quién te cae bien y quien no; entonces, tú no tengas miedo' [...] Esa ha sido la cosa más importante que le hemos enseñado a Yadira, o sea, que pueda tomar sus decisiones.

Con respecto al tema de la sexualidad, Diana me comenta: 
Yadira no tiene hermanas..., tiene primas, y a ellas les platica miles de cosas que a mí no me platica y eso lo sé; pero al menos tiene la confianza de decirme: 'oye, fíjate que fulanito de tal me gusta', y yo: 'a ver, enséñamelo, a ver si está guapo'. De pronto, pues sí te pones a pensar que van a venir otros momentos de la vida, de sexualidad, de cosas así, pero pues hemos tratado de darle las herramientas necesarias para que pueda tener una relación bien, informada más que nada $[\ldots]$

En este enunciado de Diana se ve cómo al posicionarse ante los cambios en la sexualidad, éstos no se construyen desde la oposición entre el "algún día" y el "ahora", sino que se ven como parte de un proceso continuo donde lo que está sucediendo se considera la antesala de lo que sucederá más adelante. Esta idea se asemeja al discurso de la progresión heterosexual descrito por Hauge (2009). A pesar de esta apertura en el tratamiento de la sexualidad, Yadira no se presenta discursivamente como una chica sexualmente activa ni con demasiadas curiosidades en relación con el tema:

No, es que yo no soy de ese tipo de niñas que ahora sí que les anda la hormona loca por los niños; no. Nunca me ha llamado la atención ser así, porque por ejemplo, en la secundaria decían que yo le gustaba a un niño de primero. Y yo así de 'ah, padre, ¿no?', pero no me llamó la atención. Y, o sea, mis amigas son así de 'iqué crees que le dije!'y yo así de: ‘¿qué?’, o sea, aburrida. Sí las escucho y todo, pero no me gusta ser como ellas.

Yadira se posiciona ante la sexualidad desde un lugar diferente al de las chicas de "la hormona loca", marcando una distancia respecto a ellas. A través de este discurso, se está construyendo desde un lugar que podría interpretarse como una manifestación más de su posición de sujeto autodeterminado: "la hormona loca" indica descontrol, y Yadira prefiere un acercamiento a la sexualidad a través de un manejo informado y racional de la misma.

A modo de síntesis, podemos decir entonces que en esta familia la fiesta de 15 años se utiliza estratégicamente como un recurso performativo para construir una subjetividad basada en el estilo propio y la autodeterminación. La quinceañera rechaza el uso de ciertos símbolos de las fiestas típicas y los sustituye por otros símbolos, ensayando una manera distinta de representar su feminidad adolescente, donde las identificaciones de clase se dan justamente en torno a estos valores de rechazo a la formalidad y los patrones preestablecidos. La construcción de esta posición de sujeto autodeterminado se refleja también en la manera en que se naturalizan las prácticas de heterofeminidad relacionadas con la transición a la adolescencia, a través de un manejo racional e informado de la sexualidad.

\section{CONCLUSIONES}

El análisis de estos casos permite confirmar que la celebración de los 15 años funciona como un dispositivo cultural muy fuerte de construcción del género y la diferencia sexual en México, incluso para los grupos que se resisten a aceptar el significado tradicional de estas fiestas. Las dos familias estudiadas, autodenominadas de clase media, comparten una representación muy clara de algo que es considerado una fiesta típica de 15 años: la adolescente presentada en sociedad, vestida de largo, bailando un vals, siendo centro de atención de todos, rodeada de una atmósfera 
de formalidad y elegancia, cambiando sus zapatos de niña por zapatillas de tacón y recibiendo su última muñeca como símbolo de abandono de la niñez. Mis entrevistados, sin embargo, cuestionan el sentido de estas prácticas y las critican fuertemente, considerándolas ajenas a sus estilos de vida, y atribuyendo esta forma típica de celebrar a familias populares o cercanas a las tradiciones, con las cuales ellos, en particular, no se identifican. Esto significa que la norma acerca de la transición ritualizada y solemne en la vida femenina se desestabiliza y pierde fuerza para estas familias, que construyen sus identificaciones como clase media desde códigos vinculados a lo moderno, lo informal y el rechazo a las presiones sociales.

Apartarse del patrón normativo de actuación de la feminidad adolescente según las fiestas de 15 años, sin embargo, tampoco es una decisión voluntaria e individual de estas familias. Ellas están insertas en un contexto social donde existe una multiplicidad de prácticas de consumo que funcionan como opciones para construir y legitimar estilos de vida. En este panorama, la complejización de los discursos relacionados con la feminidad adolescente hace que cada familia tenga que buscar y construir sus propios recursos y estrategias para entender y "hacer" la transición de las quinceañeras, citando la norma a través de prácticas alternativas. En los dos casos se marca, con algún tipo de celebración, la naturaleza excepcional de este momento de la vida: en el caso de Carla con un viaje familiar; en el de Yadira con una fiesta temática. En cada uno de ellos, las familias justifican la legitimidad de las prácticas elegidas desde la coherencia con sus valores, posicionándose reflexivamente ante estas celebraciones y rechazando la idea de seguir un ritual o imitar un patrón. La transición entre la niñez y la adolescencia se produce a través de la construcción de diferentes posiciones de sujeto en las dos familias: Carla es para su madre básicamente "una menor de edad", que depende todavía de sus papás, tanto en términos económicos como en toma de decisiones, $y$ en este sentido no la enuncian desde el cambio, sino desde la permanencia en un estatus infantil; mientras que Yadira se ve a sí misma y es vista por sus padres como un sujeto autónomo, que apenas se encuentra en la antesala de algunas prácticas asociadas a la adolescencia.

La ausencia de una normativa única aceptable para dar sentido a la transición adolescente implica que se generen entonces nuevas formas de control y relación con las normas, sobre todo en lo referido al acceso a la sexualidad y al posicionamiento dentro de los discursos de heterofeminidad. En el caso de Carla, este control se manifiesta a través del conflicto entre la madre y el padre, donde éste último quiere que conozca el mundo y tenga nuevas experiencias, mientras que la madre impone su autoridad para mantenerla bajo su dominio y vigilancia; y en el caso de Yadira, por el manejo racional, informado y controlado, que forma parte de su construcción como sujeto autodeterminado que toma sus decisiones.

Como acotación final me gustaría señalar que la aproximación a estos procesos de construcción de la feminidad adolescente, teniendo en cuenta la relación entre los conceptos de posiciones de sujeto, interpelación, performatividad y cita, ha permitido reflejar parte de la complejidad de los procesos de intersección entre el género, la edad y la clase social en el contexto mexicano actual, 
caracterizando no sólo las prácticas que reproducen una norma o patrón fácilmente identificable, sino también algunas de las variantes que subvierten dicha norma y resignifican la transición.

Espero entonces que este trabajo contribuya de algún modo al desarrollo de nuevas perspectivas analíticas donde las feminidades adolescentes se aborden como construcciones subjetivas, más allá de las problemáticas del embarazo no deseado y las enfermedades de transmisión sexual que comúnmente se estudian de manera aislada. Es importante, en este sentido, proponer temas donde se analicen los discursos y las prácticas performativas y citacionales a través de las cuales estas subjetividades se conforman, pensando en torno de las mujeres adolescentes desde la complejidad de relaciones sociales que las constituyen. Al respecto, es importante profundizar en los análisis del contexto familiar, donde las adolescentes se involucran también en interacciones intergeneracionales que no han sido muy estudiadas por las ciencias sociales en general. ¿े 


\section{BIBLIOGRAFÍA}

Althusser, Louis (1974), Ideología y aparatos ideológicos de Estado. Buenos Aires, Ediciones Nueva Visión.

Austin, John (2008 [1971]), Cómo hacer cosas con palabras. Buenos Aires, Paidós.

Biggs, Simon (2004), “Age, gender, narratives, and masquerades”, en Journal of Aging Studies, núm.18, pp. $45-58$.

Butler, Judith (1990), Gender Trouble, London, Routledge.

Butler, Judith (2002), Cuerpos que importan. Sobre los límites materiales y discursivos del sexo. Buenos Aires, Paidós.

De Beauvoir, Simone (1997 [1949]), El segundo sexo. México, Siglo Veinte.

Derrida, Jacques (1998 [1972]), “Firma, acontecimiento y contexto”, en Márgenes de la filosofía. Madrid, Cátedra, pp. 347-372.

Eckert, Penelope (2002), “Language and Gender in Adolescence”, en J. Holmes y M. Meyerhoff (eds.), The Handbook of Language and Gender. Oxford, Blackwell, pp. 381-400.

Hauge, Mona-Iren (2009), "Bodily practices and discourses of hetero-femininity: girls' constitution of subjectivities in their social transition between childhood and adolescence”, en Gender and Education, vol. 21, núm. 3, pp. 293-307.

Jørgensen, Marianne y Louise Phillips (2002), Discourse Analysis as Theory and Method. London, Sage Publications.

Meira, Cecilia (2009), "Empieza la aventura de la vida: La concepción social de las mujeres jóvenes en Cuajimalpa y Álvaro Obregón a partir de las fiestas de 15 años". México, Universidad Autónoma Metropolitana Iztapalapa, tesis de licenciatura. 
Nieto, Raúl (2001), “Ritualidad secular, prácticas populares y videocultura en la ciudad de México”, en Alteridades, vol. 11, núm. 22, pp. 49-57.

Palencia, Mercedes y Víctor Gruel (2006), “Algunas visiones sobre un mismo ritual: la fiesta de quince años”, en Temas Sociológicos, núm. 11, pp. 221-240.

Nikander, Pirjo (2009), "Doing change and continuity: age identity and the micro-macro divide", en Ageing \& Society, núm. 29, pp. 863-881.

Ringrose, Jessica (2011), “Are You Sexy, Flirty, Or A Slut? Exploring 'Sexualization’ and How Teen Girls Perform/Negotiate Digital Sexual Identity on Social Networking Sites”, en R. Gill y C. Scharff(eds.), New Femininities. Postfeminism, Neoliberalism and Subjectivity. New York, Palgrave Macmillan, pp. 99-116.

Ruiz, Emma (2001), “Adolescencia femenina y ritual. La celebración de las quinceañeras en algunas comunidades de México”, en Espiral, vol. 7, núm. 20, pp. 189-222.

Salih, Sarah (2002), Judith Butler, London, Routledge.

Sarricolea, Juan Miguel y Albertina Ortega (2009), "Una mirada antropológica al estudio de los rituales festivos. La fiesta de XV años”, en Dimensión antropológica, vol. 16, núm. 45, pp. 131-154.

Stern, Claudio (2007), "Estereotipos de género, relaciones sexuales y embarazo adolescente en las vidas de jóvenes de diferentes contextos socioculturales en México”, en Estudios Sociológicos, enero-abril, vol. XXV, núm. 73, pp. 105-129.

Tuñón, Esperanza y Enrique Eroza (2001), “Género y sexualidad adolescente. La búsqueda de un conocimiento huidizo”, en Estudios Sociológicos, vol. XIX, núm. 55, pp. 209-226.

\section{Fecha de recepción: 8 de agosto de 2014}

Fecha de aceptación: 13 de octubre de 2014 